\title{
Prevalence and associated risk factors of dry eye disease in 16 northern West bank towns in Palestine: a cross-sectional study
}

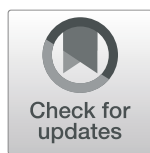

Yousef Shanti ${ }^{1,2^{*}+}$, Reham Shehada ${ }^{2,3+}$, May M. Bakkar ${ }^{4}$ and Jamal Qaddumi ${ }^{5}$

\begin{abstract}
Background: Dry Eye Disease (DED) is a multifactorial disease of the interpalpebral ocular surface and tear film that leads to discomfort, fatigue and disturbance in vision. DED affects patients' quality of life and leads eventually to decrease of productivity. Moreover, it has a considerable socioeconomic burden. It is a growing underdiagnosed health issue and the possible associated risk factors are very common and keep growing worldwide.

Purpose: To assess the prevalence of DED and potential associated risk factors in the Northern West Bank of Palestine.

Methods: A cross sectional study was conducted in 16 selected towns in Northern West Bank governorates during December 2016 to September 2017. An interviewer-assisted Ocular Surface Disease Index (OSDI) questionnaire was used to study DED symptoms in the study population. Further evaluation of clinical signs of DED was performed using the following objective tests: tear film break-up time (TBUT), fluorescein corneal staining (FL/S) and Schirmer test. Subjects with an OSDI score of 13 or above were considered symptomatic of DED, and DED was defined if an OSDI score $\geq 13$ is accompanied by at least one of the following signs in the worse eye: TBUT $\leq 10 \mathrm{~s}$, Schirmer score $\leq 5 \mathrm{~mm}$ and fluorescein corneal staining $\geq$ grade 1 .

Results: Seven hundred sixty-nine subjects were recruited from the general non-clinical population in the West Bank. The mean age of participants was $43.61 \pm 18.57$ years ranging from 18 to 90 years. Females constitute $52.7 \%$ of the study population. Based on the diagnostic criteria, the prevalence of DED was 64\% (95\% confidence interval 60.6-67.3). DED was significantly associated with female gender $p=(0.001)$ and older age $p=(0.001)$.

Conclusion: The prevalence of DED is high in the study population. Older age and female gender were associated risk factors with the development of DED.
\end{abstract}

Keywords: Dry eye disease, Prevalence, Risk factors, Palestine

\section{Background}

Dry eye disease (DED) is a common ocular surface disorder that considered a public health problem due to its impact on vision-related quality of life of the affected subjects $[1,2]$.According to the recent official report of the International Dry Eye Workshop (DEWS 2017), that based on summary of the findings of current research,

\footnotetext{
* Correspondence: yousef.isam.shanti@gmail.com; yousef.shanti@najah.edu ${ }^{\dagger}$ Yousef Shanti and Reham Shehada contributed equally to this work. 'Department of Ophthalmology, An-Najah National University Hospital, 44839 Nablus, Palestine

${ }^{2}$ Department of Medicine, College of Medicine and Health Sciences, An-Najah National University, 44839 Nablus, Palestine

Full list of author information is available at the end of the article
}

DED was defined as "a multifactorial disease of the tears and ocular surface that is associated with hyperosmolarity of tear film which in turn leads to inflammation and damage of the ocular surface that accompanied with ocular symptoms of discomfort, fatigue and disturbance in visioin" [1].

The prevalence of DED has been reported in many countries around the world, with a range of between 9.5-90\% [3-12]. This variation has been suggested to be influenced by geographical location, the variety of the population studied, variation in diagnostic criteria used with an observed lack of standard diagnostic criteria across all studied. In general, it was reported that

(C) The Author(s). 2020 Open Access This article is distributed under the terms of the Creative Commons Attribution 4.0 International License (http://creativecommons.org/licenses/by/4.0/), which permits unrestricted use, distribution, and 
prevalence of DED more prevalent in Asian countries compared to Western countries [13].

Epidemiologic studies showed that the disease is more prevalent among women (particularly post menopause) [14] and elderly population [15]. Additionally, a group of risk factors have been reported to be associated with DED. Those include environmental factors such as extreme temperature and reduced relative humidity [16], use of video display terminals (VDT) [17], smoking [18], refractive surgery such as LASIK $[19,20]$, contact lens wear [21], and uptake of certain medications such as antihistamines [22], beta-blockers [23] and oral contraceptives [6]. DED was also reported to occur with anxiety disorders, sleep disorders and depression $[24,25]$.

DED can be assessed based on a combination of symptoms and signs. However, several studies reported poor correlation between DED symptoms and signs [26-28]. Dryness symptoms could be assessed systematically using validated questionnaires that include questions allow for the monitoring of dryness symptoms and their frequency and or their severity over time [29]. Examples of these questionnaires include Ocular Surface Disease Index (OSDI) questionnaire, Dry Eye Questionnaire (DEQ), MacMonnies dry eye questionnaire and Standard Patient Evaluation of Eye Dryness (SPEED) questionnaire [30].

Clinical signs of DED are routinely assessed using a set of tests that include measure of tear film stability as in tear film break-up time test (TBUT), assessment of ocular surface desiccation through corneal and conjunctival staining by fluorescein or lissamine green stains, tear volume which can be estimated with Schirmer test or observation of lower tear film meniscus volume under a slit-lamp [31]. The quality of the tear film can also be assessed and monitored by measuring tear film osmolarity that based on the number of charged particles in a small tear sample measured by osmometer [31, 32].

A review of the literature showed that the prevalence of DED in the Middle East has not been frequently studied. However, according to the few studies reported in the region; the prevalence was noticeably high. For example, in the Kingdom of Saudi Arabia (KSA), DED was reported at a prevalence of $93.2 \%$ in one city on the basis of presence of one or more DED symptoms occurring often or most of the time, along with presence of one or more of the dryness signs revealed by clinical tests [33]. In another recent study in KSA but in a different region (Al-Ahsa) the prevalence of dry eye disease was reported at $32 \%$ based on presence of one or more of DED symptoms in a frequency of often or constantly [34]. In a cross sectional study that conducted in Jordan and based on OSDI questionnaire, it was reported that $59 \%$ of the study population reported an OSDI score equal or greater than 20 and accordingly considered DED symptomatic [3]. In Iran, a study was conducted among 40-64 years old population in one city reported a prevalence of DED of $8.7 \%$ based on an OSDI score of 23 or higher and presence of one positive sign of DED [4].

The prevalence of DED in Palestine has not been studied before. Therefore, this study aims to study the prevalence of DED and to investigate possible risk factors of the disease in a general non-clinical population in Palestine.

\section{Methods}

\section{Study population}

Multistage sampling method -based on the Palestinian central bureau of statistics sampling frame- was used to identify the Palestinian towns participating in the study. Sixteen towns in Northern six West Bank governorates were randomly selected to enroll in the study. Participants were randomly selected and invited from phone directory of 16 towns in Northern six West Bank governorates to attend a free medical event held in municipal councils of their towns. The maximum number of participants who fit the study inclusion criteria was 900 . However, the final number of respondents who were able to attend the free medical day was 769 from 16 towns in Northern West Bank governorates.

The needed number of participants depended on the percentage of Palestinians in each city. Given that the number of Palestinians in the selected cities in the west bank is about 391.821 people, a minimum complete data from 384 participants would be needed. Using http:// www.raosoft.com/samplesize.html, this would allow the percentage of correct answers to be estimated with a 95\% confidence interval and margin-of-error of at most $\pm 5 \%$. So, 769 participants thought to be adequate to enrol in the study.

The cross-sectional study was conducted between September 2016 and January 2017.Only subjects aged 18 and above were interviewed for the study.

\section{Exclusion criteria}

Exclusion criteria included patients who are contact lens wearers, those who underwent refractive surgery procedures and those with an active ocular surface disease and any other conditions that may interfere with development of DED. Subjects with previous diagnosis of DED were included in the study.

\section{The questionnaire}

Participants were interviewed in using the Arabic version of the OSDI questionnaire by trained surveyors. A pilot study revealed that the Arabic questionnaire was easily administered, socio-culturally acceptable and understandable [3]. 
The participants asked to rate their own ocular symptoms over the preceding week. Each time a participant indicated the existing of dry eye symptom, he/she was further asked to grade its frequency on a scale of 0 to 4 , where 0 indicates none of the time; 1 , some of the time; 2 , half of the time; 3 , most of the time; and 4 , all of the time. To calculate the OSDI score, total points of patient's responses were multiplied by 25 and then divided by the total number of responses [35].

Additionally, other demographic data (age, gender), medical and ocular history were acquired from each participant. The risk factors evaluated were age, gender, VDT use and smoking.

\section{Examinations}

A sequence of ocular examinations was performed for each participant. Those include best corrected visual acuity which was assessed using Snellen visual acuity chart, manifest refraction using retinoscopy. Slit-lamp biomicroscopy was used for assessment of adnexa and ocular surface health, corneal staining and dry eye testing.

Dry eye objective tests were performed in the following order: measurement of fluorescein-assisted tear film break-up time TBUT, meibomian glands evaluation and Schirmer test. TBUT was performed by fluorescein strip that was slightly wetted with non-preserved saline and administered to the lower conjunctiva. TBUT was then determined by counting the time in seconds between the last blink and the appearance of the first dry spot in the pre-corneal tear film observed by slit-lamp with blue light filter. This process was repeated three times for each eye and an average of the three values was recorded for each eye. Level of staining on the cornea was graded using Efron scale [31].

Schirmer test was performed without anesthesia using a sterile Schirmer strip that was placed at the junction of the lateral one third to medial two thirds of the lower lid and left for $5 \mathrm{~min}$ while the patient blink normally. The length of wetted Schirmer strip was recorded in millimeters.

For all given dry eye objective tests used in this study, both eyes were examined and data was recorded for both eyes. In cases of variation between the two eyes, data from the worse eye was used for statistical analysis.

\section{Diagnostic criteria}

Presence of DED was investigated through evaluation for DED symptoms and clinical signs. DED was defined using diagnostic criteria recommended by DEWS 2017 report $[1,36]$. DED diagnosis was confirmed by the presence of subjective DED symptoms revealed with an OSDI score of $\geq 13$ which is accompanied by at least one of the following objective DED signs in the worse eye:
TBUT $\leq 10 \mathrm{~s}$, Schirmer score $\leq 5 \mathrm{~mm}$ and fluorescein corneal staining $\geq$ grade $1[4,37,38]$.

\section{Statistical analysis}

Data were analyzed using the statistical Package for Social Sciences (SPSS) software version 21.0 (SPSSJ: Inc., Chicago, IL, USA). Chi-square test was applied on the categorical variables. Prevalence of DED in the studied population and confidence intervals (CIs) were calculated for risk factors. Odds ratio and associated risk factors with the DED were evaluated using bivariate and multivariate logistic regression analysis at 95\% CI. A pvalue of less than 0.05 was considered statistically significant.

\section{Results}

\section{Participant characteristics}

The study was conducted during December 2016 to September 2017. A total of 769 participants were recruited from six governorates in Northern West Bank. The mean age of all participants was $43.61 \pm 18.57$ years with a range of 18 to 90 years. Of all study population, $405(52.7 \%)$ subjects were females and 364 (47.3\%) were males. Of the study population, 131 (17\%) reported having diabetes milletus (DM), 161 (20.9\%) reported having hypertension (HTN).

The demographic characteristics of the study population are shown in Table 1.

\section{Prevalence of dry eye disease}

Based on the DED diagnostic criteria clarified in the methodology section; of an OSDI score $\geq 13$ and presence of one or more clinical signs of DED, the overall prevalence of DED was $64 \%(95 \%$ confidence interval 60.6-67.3) in the study population. The average age of patients with DED was $45.24 \pm 18.8$ years. Table 2 shows the distribution of DED by age groups and gender.

DED was significantly more prevalent in older age group $>45$ years $(p=0.002)$ and in females than males in all age groups $(p=0.00)$.

The prevalence of DED (an OSDI $\geq 13$ and presence of at least 1 clinical sign) and its signs are summarized in Table 3. From the overall study population of 769 subjects, the proportion of subjects with an OSDI score equal or greater than 13 (the cut off value) was $71 \%$.The most prevalent DED sign is abnormal TBUT $(\leq 10 \mathrm{~s})$ as it is revealed among males and females within all age groups. Whereas, Schirmer test score of $\leq 5 \mathrm{~mm}$ was the least prevalent sign among all the study population.

\section{OSDI score results}

The calculated mean OSDI score for all participants was $27.7 \pm 21.4$. The mean OSDI score in the definite DED 
Table 1 participants' characteristics $(n=769)$

\begin{tabular}{ll}
\hline Variable & No. (\%) of respondents \\
\hline Gender & $364(47.3)$ \\
Male & $405(52.7)$ \\
Female & \\
Age group(yrs) & $179(23.3)$ \\
18-25 & $225(29.3)$ \\
$26-45$ & $365(47.5)$ \\
$>45$ & \\
Smoking & $542(70.5)$ \\
Non-Smokers & $227(29.5)$ \\
Smokers & \\
Education level & $67(8.7)$ \\
Illiterate & $481(62.5)$ \\
High school & $221(28.8)$ \\
Higher education & \\
Residence & $325(42.26)$ \\
Jenin & $158(20.5)$ \\
Tulkarem & $150(19.5)$ \\
Nablus & $56(7.3)$ \\
Tubas & $42(5.5)$ \\
Qalqilia & $38(4.9)$ \\
Salfit &
\end{tabular}

group was $37 \pm 19$.For the non-dry eye group, the average OSDI score was $11 \pm 14$.

From the overall study population of 769 subjects, the proportion of subjects with an OSDI score equal or greater than 13 (the cut off value) was $71 \%$. The frequency of different levels of dryness symptoms severity based on OSDI score is shown in Table 4.

\section{DED objective signs}

In definite DED group the mean TBUT was $5 \pm 2.4 \mathrm{~s}$, the mean Schirmer test value was $17.4 \pm 8.7 \mathrm{~mm}$.

\section{Risk factors of dry eye disease}

The risk factors associated with the definite DED were evaluated using a bivariate and a multivariate logistic regression analysis. Significant odds of having DED were associated with older age (older than 45) and female gender (Table 5).Whereas, definite DED was not significantly associated with smoking and presence of systemic disease.

The average daily usage of VDT in the DED and nonDED groups was 1.9 and $1.6 \mathrm{~h}$, respectively. However, VDT usage was not significantly correlated with the development of DED.

\section{Discussion}

Few studies have investigated the prevalence of DED in the Middle East. This is the first population-based study regarding prevalence and risk factors of DED in Palestine. The study combined both subjective and objective clinical tests to confirm the diagnosis of DED based on the diagnostic criteria recommended by latest DEWS guidelines published in 2017 [1]. Associated potential risk factors with the development of DED were also evaluated.

In the study, the OSDI questionnaire was used to assess the presence of symptomatic DED. Patients also underwent an assessment of the DED clinical signs those include corneal staining, Schirmer test and FTBUT. DED was confirmed by presence of dryness symptoms and at least one clinical sign.

The data reveals that DED is a prevalent disease in west Palestine; where $69 \%$ of the study population reported symptoms of the disease and manifested DED clinical signs. This prevalence is higher than other reports in the region with similar arid climate $[3,34]$. The high prevalence might be attributed to several factors mainly related to the arid climate with temperature ranging from 30 to $40{ }^{\circ} \mathrm{C}$ during summer seasons.

Furthermore, the psychological aftermaths of the Palestinian-Israeli Conflict which was suggested as affecting the Palestinians in a wider range could have increased the levels of stress and anxiety among this population [39]. The psychological aftermaths of the conflict and violence including posttraumatic stress disorders could also have strong public health impact [39],

Table 2 distribution of definite dry eye disease (DED) by age group and gender

\begin{tabular}{|c|c|c|c|c|c|c|}
\hline \multirow{3}{*}{$\begin{array}{l}\text { Age } \\
\text { groups } \\
\text { (years) }\end{array}$} & \multicolumn{6}{|l|}{ DED } \\
\hline & \multicolumn{3}{|l|}{ Yes } & \multicolumn{3}{|l|}{ No } \\
\hline & Male (n) & Female (n) & Total (n) & Male (n) & Female (n) & Total (n) \\
\hline $18-25$ & 45 & 62 & 107 & 41 & 31 & 72 \\
\hline $26-45$ & 57 & 70 & 127 & 53 & 45 & 98 \\
\hline$>45$ & 105 & 153 & 258 & 63 & 44 & 107 \\
\hline Total (n) & 207 & 285 & 492 & 157 & 120 & 277 \\
\hline
\end{tabular}


Table 3 The prevalence (\%) of DED and its signs and symptoms by age and gender. Data are presented for the worse eye only

\begin{tabular}{|c|c|c|c|c|c|c|}
\hline \multirow[t]{2}{*}{ 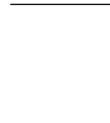 } & \multirow[t]{2}{*}{$\mathrm{N}$} & \multirow{2}{*}{$\begin{array}{l}\text { OSDI score } \geq 13 \\
N(\%) \\
(95 \% \mathrm{Cl})\end{array}$} & \multirow{2}{*}{$\begin{array}{l}\text { TBUT } \leq 10 \mathrm{~s} \\
N(\%) \\
(95 \% \mathrm{Cl})\end{array}$} & \multirow{2}{*}{$\begin{array}{l}\text { Schirmer test } \leq 5 \mathrm{~mm} \\
\mathrm{~N}(\%) \\
(95 \% \mathrm{Cl})\end{array}$} & \multirow{2}{*}{$\begin{array}{l}\text { Corneal fluorescein staining } \geq 1 \\
\mathrm{~N}(\%) \\
(95 \% \mathrm{Cl})\end{array}$} & \multirow{2}{*}{$\begin{array}{l}\text { DED } \\
\text { N (\%) } \\
(95 \% \mathrm{Cl})\end{array}$} \\
\hline & & & & & & \\
\hline \multicolumn{7}{|c|}{ Age groups } \\
\hline \multirow[t]{2}{*}{$18-25$} & 179 & 107 (60\%) & $123(68.8 \%)$ & $10(5.6 \%)$ & $90(50.4 \%)$ & 107 (59.8\%) \\
\hline & & $(52.5-66)$ & $(64-73.3)$ & $(2.2-9.2)$ & $(43.4-56.5)$ & $(52.5-66.7)$ \\
\hline \multirow[t]{2}{*}{$26-45$} & 225 & $126(56.2 \%)$ & 170 (75.6\%) & 22 (9.8\%) & 132(59.1\%) & 127 (56.4\%) \\
\hline & & $(50-63.6)$ & $(73-77.9)$ & $(6.1-14.8)$ & $(52.9-64.1)$ & $(50.2-63.6)$ \\
\hline \multirow[t]{2}{*}{$>45$} & 365 & $256(70.8 \%)$ & $270(74.2 \%)$ & $39(0.7 \%)$ & $273(75.1 \%)$ & $258(70.7 \%)$ \\
\hline & & $(65.7-74.7)$ & $(71.5-76.4)$ & $(7.7-14)$ & $(72.9-77.2)$ & $(66-75.3)$ \\
\hline \multirow[t]{2}{*}{ Male } & 364 & 205 (56.5\%) & 185 (51\%) & 19 (5.2\%) & 232 (64.1\%) & 207 (57\%) \\
\hline & & $(51.8-60.9)$ & $(48.2-54)$ & $(2.8-7.4)$ & $(60.2-67.6)$ & $(52-61.5)$ \\
\hline \multirow[t]{2}{*}{ Female } & 405 & 286 (70.8\%) & $223(55.3 \%)$ & $52(12.8 \%)$ & 264 (65.2\%) & $285(70.4 \%)$ \\
\hline & & $(66.4-75.3)$ & $(53.3-57.3)$ & $(9.9-16.3)$ & $(62-68.9)$ & $(66.4-75.1)$ \\
\hline
\end{tabular}

and according to the ophthalmic literature, individuals with anxiety and stress, with or without psychiatric disease, are more expected to experience DED [24, 25, 40].

The prevalence of DED varies widely between different population-based studies, which make it difficult to compare findings from these studies. The variability in prevalence of DED may contribute to the type of targeted population (clinical or non-clinical), studied population's age group and differences in DED diagnostic criteria that may rely on subjective reported symptoms detected by questionnaire or usage of objective clinical tests. Table 6 summarizes results from different studies around the world on the prevalence of DED.

In this study, definite DED diagnosis was more prevalent in subjects older than 45 years. This in agreement with many reports that found age related to DED development $[3,4,33,34]$. The results also showed an association between DED diagnosis and female gender as females have 1.5 times higher risk of developing DED compared to males. This finding could be explained by use of hormones for contraception or infertility in the younger women age group and the impact of these hormones on the female's lacrimal gland, goblet cell function, MG and ocular surface sensitivity that may contribute to dry eye symptoms [11]. In women within the older age group, lower levels of estrogens and androgen may lead to inadequate lacrimal gland secretion that associate with aqueous deficient DED [51].The impact of gender on the

Table 4 Severity of DED symptoms based on OSDI score

\begin{tabular}{ll}
\hline Level of OSDI score & $\mathrm{N}(\%)$ \\
\hline Normal (0-12) & $224(29.1)$ \\
Mild (13-22) & $150(19.5)$ \\
Moderate (23-32) & $122(15.9)$ \\
Severe (33-100) & $273(35.5)$ \\
\hline
\end{tabular}

development of DED varies across studies. Consistent with the current study, most studies reported that DED occurs more likely among females $[3,4,6,34,46,48,49]$.

The results of this study showed no association between DED and smoking habit. This finding is in agreement with other reports where smoking was not associated with the development of DED [3]. However, few studies reported an association of smoking with DED [6, 34].

There was also no association between DED and VDT usage.This findingcontradicts with many published reports where VDT plays a role with development of DED [10, 52]. In the current study, this may explained by that $47.5 \%$ of the study population are within the older age group ( $>45$ years), where VDT usage is more common in younger population.

Table 5 logistic regression analysis of risk factors associated with definite DED

\begin{tabular}{|c|c|c|c|}
\hline Risk factors & Definite DED (n) & $P$ value & Adjusted OR (95\% Cl) \\
\hline Age (years) & & $0.001^{*}$ & $1.018(1.008-1.029)$ \\
\hline $18-25$ & 107 & & \\
\hline $26-45$ & 127 & & \\
\hline$>45$ & 258 & & \\
\hline Gender & & $0.001^{*}$ & $0.524(0.364-0.755)$ \\
\hline Male & 207 & & \\
\hline Female & 285 & & \\
\hline VDT use (yes vs. No) & 208 & 0.231 & 1.040 (0.976-1.108) \\
\hline Smoking & 132 & 0.854 & $0.964(0.652-1.426)$ \\
\hline \multicolumn{4}{|l|}{ Systemic disease } \\
\hline DM & 88 & 0.841 & $1.047(0.669-1.637)$ \\
\hline Hypertension & 108 & 0.433 & $1.190(0.771-1.836)$ \\
\hline
\end{tabular}


Table 6 prevalence of DED from different studies around the world

\begin{tabular}{|c|c|c|c|c|c|}
\hline Country/area & Sample number & Prevalence & Diagnostic criteria & $\begin{array}{l}\text { Age group } \\
\text { (yrs) }\end{array}$ & Authors (year) \\
\hline This study/ Palestine & 769 & $69 \%$ & $\begin{array}{l}\text { One or more symptoms often or all most } \\
\text { thetime, accompanied by at least one sign } \\
\text { (TBUT, Schirmer test and FL/S of the cornea) }\end{array}$ & $18-90$ & \\
\hline Jordan & 1039 & $59 \%$ & $\begin{array}{l}\text { Symptoms only using OSDI questionnaire, } \\
\text { a score of } 20 \text { or above considered } \\
\text { symptomatic DED. }\end{array}$ & $\geq 18$ & $\begin{array}{l}\text { Bakkar et al. } \\
\text { (2016) [3]. }\end{array}$ \\
\hline Saudi Arabia (Jeddah) & 251 & $93.2 \%$ & $\begin{array}{l}\text { One or more symptom often or all most time, } \\
\text { accompanied by at least one signs (TBUT, } \\
\text { Schirmer test and FL/S of the cornea }\end{array}$ & $7-78$ & $\begin{array}{l}\text { Bukhari et al. } \\
\text { (2009) [33]. }\end{array}$ \\
\hline Saudi Arabia (Al-Ahsa) & 1858 & $32.1 \%$ & $\begin{array}{l}\text { 6-item questionnaire. DED is determined by } \\
\text { presence of one or more of the six DES } \\
\text { symptoms often or constantly. }\end{array}$ & $16-78$ & $\begin{array}{l}\text { Alshamrani et al. } \\
\text { (2017) [34]. }\end{array}$ \\
\hline Iran, Shahroud & 1008 & $8.7 \%$ & $\begin{array}{l}\text { Symptoms using OSDI questionnaire and } \\
\text { presence of at least one of objective signs } \\
\text { (Schirmer test, TBUT, fluorescein and rose } \\
\text { Bengal staining). }\end{array}$ & $40-64$ & $\begin{array}{l}\text { Hashemi et al. } \\
\text { (2014) [4]. }\end{array}$ \\
\hline $\begin{array}{l}\text { United States/female } \\
\text { population only }\end{array}$ & 39,876 & $7.8 \%$ & $\begin{array}{l}\text { in the presence of either a prior clinical diagnosis } \\
\text { of DES or intense symptoms (both irritation and } \\
\text { dryness whether many times or all the times) }\end{array}$ & $45-84$ & $\begin{array}{l}\text { Schaumberg } \\
\text { et al.(2003) [41]. }\end{array}$ \\
\hline $\begin{array}{l}\text { United States/ Hispanic } \\
\text { population }\end{array}$ & 463 & $43.6 \%$ & $\begin{array}{l}\text { One simple question about symptomatic dryness } \\
\text { was asked. } \\
\text { "How often do you have dryness?" The answers } \\
\text { were forced choice: never, seldom, sometimes, } \\
\text { frequently, or always. }\end{array}$ & $4-85$ & $\begin{array}{l}\text { Hom et al. } \\
\text { (2005) [42]. }\end{array}$ \\
\hline USA, Wisconsin & 3722 & $14.4 \%$ & $\begin{array}{l}\text { Self-recorded history of DED through the } \\
\text { previous } 3 \text { months }\end{array}$ & $48-91$ & $\begin{array}{l}\text { Moss et al. } \\
\text { (2000) [6]. }\end{array}$ \\
\hline USA, Maryland & 2420 & $14.6 \%$ & $\begin{array}{l}\text { One or more dry eye symptoms often or all } \\
\text { the time (six items) Meibomian glands } \\
\text { assessment, rose Bengal, Schirmer's test. }\end{array}$ & $65-84$ & $\begin{array}{l}\text { Schein et al. } \\
\text { (1997) [43]. }\end{array}$ \\
\hline Indonesia/Sumatra & 1058 & $27.5 \%$ & $\begin{array}{l}\text { One or more symptoms many times or all } \\
\text { the time using a six item validated questionnaire. }\end{array}$ & $\geq 21$ & $\begin{array}{l}\text { Lee et al. } \\
\text { (2002) [5]. }\end{array}$ \\
\hline Japan/Tokyo & 598 & $33 \%$ & Self-administered Questionnaire & $20-49$ & $\begin{array}{l}\text { Shimmura et al. } \\
\text { (1999) [44]. }\end{array}$ \\
\hline Japan & $\begin{array}{l}113 \text { (Left eye } \\
\text { only) }\end{array}$ & $73.5 \%$ & $\begin{array}{l}\text { Japanese diagnostic criteria of dry eye } \\
\text { (Schirmer test, TBUT, FL/S of the cornea) }\end{array}$ & $\geq 60$ & $\begin{array}{l}\text { Uchino et al. } \\
\text { (2006) [45]. }\end{array}$ \\
\hline Australia & 1174 & $57.5 \%$ & Dry eye questionnaire & $\geq 50$ & $\begin{array}{l}\text { Chia et al. } \\
\text { (2003) [46]. }\end{array}$ \\
\hline Australia & 1584 & $10.8 \%$ & $\begin{array}{l}\text { McMonnies dry eye questionnaire, TBUT and } \\
\text { Rose Bengal ocular surface staining }\end{array}$ & $3-96$ & $\begin{array}{l}\text { Albietz et al. } \\
\text { (2000) [47]. }\end{array}$ \\
\hline Australia/Melbourne & 926 & $\begin{array}{l}16.3 \% \text { by (Schirmer's) } \\
8.6 \% \text { by (TBUT) } 1.5 \% \\
\text { by (FL/S) } 10.8 \% \text { by } \\
\text { (rose Bengal) } 5.5 \% \text { with } \\
\text { any sever symptom }\end{array}$ & $\begin{array}{l}\text { Objective assessment Schirmers }<8 \text {, TBUT } \\
<8, \mathrm{FL} / \mathrm{S} \text {, rose bengal }>3 \text { and intense symptoms } \\
(3 \text { on a scale of } 0 \text { to } 3 \text { ) }\end{array}$ & $40-97$ & $\begin{array}{l}\text { McCarty et al. } \\
\text { (1998) [48] }\end{array}$ \\
\hline Taiwan, Taipei & 1361 & $33.7 \%$ & $\begin{array}{l}\text { Reporting one or more dry eye symptoms often } \\
\text { or all of the time. }\end{array}$ & $\geq 65$ & $\begin{array}{l}\text { Lin et al. } \\
\text { (2003) [49]. }\end{array}$ \\
\hline Thailand, Bangkok & 550 & $34 \%$ & $\begin{array}{l}\text { One symptom or more many times or most of } \\
\text { the time, TBUT, Schirmer's test, FL/S, assessment } \\
\text { of Meibomian gland }\end{array}$ & 40-78 & $\begin{array}{l}\text { Lekhanont et al. } \\
\text { (2006) [50]. }\end{array}$ \\
\hline
\end{tabular}

The current study showed that a high number of subjects had tear-film instability that characterized by abnormal TBUT of less than $10 \mathrm{~s}$ and corneal staining of a grade 1 or higher which was observed in $93 \%, 84 \%$ of subjects, receptively. Whereas, the least reported sign was Schirmer score of less than $5 \mathrm{~mm}$. This may suggest that DED in the studied population might affect the tear film quality or instability rather than the tear film quantity. However, Schirmer's score might be underestimated sign due to irritation caused by the Schirmer's strip that may induce reflex tearing which could mask the sign of reduced tear quantity on the ocular surface. It was also 
suggested in the literature that Schirmer scores have poor correlation with dry eye symptoms [53].

From the overall study population, $71 \%$ had an OSDI score of 13 or greater; a proportion higher than the prevalence of definite DED in this study. Depending only on the OSDI scores or presence of dryness symptoms to diagnose DED may result in an overestimation of the DED in the studied population. This emphasizes the need to combine both clinical signs and symptoms to define DED [54].

The study may have some limitations. The exclusion of contact lens wearers, post refractive surgery patients and patients with severe conjunctival and corneal disease might underestimate the actual prevalence of DED in the studied population. Additionally, meibomian gland dysfunction and tear film osmolarity tests were not assessed in the study population, while these tests play an important role in the accurate diagnosis of DED.

Finally, FTBUT was used in the current study. However, non-invasive BUT was recommended by DEWS II to use as it is longer than FBUT in general. However, in the same DEWS II 2017 report it was stated that "measurement of the tear breakup time with a noninvasive technique (NIBUT) is considered preferable to the FBUT and the two techniques are well correlated" [55].

\section{Conclusion}

In conclusion, this is the first study of the prevalence of DED in a previously unstudied population in Palestine. It was found that the prevalence of DED is relatively high in this study. An attempt should be performed to increase the awareness of the society with DED, so modifiable risk factors can be reduced. However, further research is required to better understand other potential risk factors associated with DED including; impact of arid environment, drug use, systemic diseases and anxiety.

\section{Abbreviations \\ Cl: Confidence intervals; DED: Dry Eye Disease; DEQ: Dry Eye Questionnaire; DEWS 2017: International Dry Eye Workshop; FL/S: Fluorescein corneal staining; IRB: Institutional Review Board; KSA: Kingdom of Saudi Arabia; OSDI: Ocular Surface Disease Index; SPEED: Standard Patient Evaluation of Eye Dryness; SPSS: The statistical Package for Social Sciences; TBUT: Tear film break-up time; VDT: Video display terminals}

\section{Acknowledgments \\ The authors would like to thank the head of optometry department (Dr. Liana Labadi) and optometry students especially Hamza Nazzalat at An-Najah National University for their organizing the free medical events where data was collected. We would like to thank Dr. Mohammad Al Qadire from Al- Bayt University (AABU) in Jordan for his assistance in statistical analysis of the data.}

\section{Authors' contributions}

YS and RS designed the study and collected the data. MB took responsibility for the data analysis, interpretation of the results and the final write-up of the manuscript. JQ took responsibility for manuscript revision. All authors read and approved the final manuscript.

\section{Funding}

No funding was received for the writing of this study.

\section{Availability of data and materials}

All data supporting the study is presented in the manuscript or available upon request from the corresponding author of this manuscript.

\section{Ethical approval and consent to participate}

The study protocol was approved by the Institutional Review Board (IRB) of An-Najah National University. The local health authorities approved the data collection and granted permission to access and use the patients' sociodemographic and clinical data. Informed written consent was obtained from all participants prior to their participation in the study, and all study methodology complied with the guidelines of the Declaration of Helsinki.

\section{Consent for publication}

Not Applicable.

\section{Competing interests}

The authors declare that they have no competing interests.

\section{Author details}

${ }^{1}$ Department of Ophthalmology, An-Najah National University Hospital, 44839 Nablus, Palestine. ${ }^{2}$ Department of Medicine, College of Medicine and Health Sciences, An-Najah National University, 44839 Nablus, Palestine. ${ }^{3}$ Department of Ophthalmology, The Islamic Hospital, Amman, Jordan. ${ }^{4}$ Faculty of Applied Medical Sciences, Department of Allied Medical Sciences, Jordan University of Science and Technology (JUST), Irbid 22110, Jordan. ${ }^{5}$ Department of Nursing, College of Medicine and Health Sciences, An-Najah National University, 44839 Nablus, Palestine.

Received: 9 July 2018 Accepted: 27 December 2019

Published online: 13 January 2020

\section{References}

1. Craig JP, Nichols KK, Akpek EK, Caffery B, Dua HS, Joo CK, et al. TFOS DEWS II definition and classification report. Ocul Surf. 2017:15:276-83.

2. Grubbs JR Jr, Tolleson-Rinehart S, Huynh K, Davis RM. A review of quality of life measures in dry eye questionnaires. Cornea. 2014:33:215-8.

3. Bakkar MM, Shihadeh WA, Haddad MF, Khader YS. Epidemiology of symptoms of dry eye disease (DED) in Jordan: a cross-sectional non-clinical population-based study. Cont Lens Anterior Eye. 2016:39:197-202.

4. Hashemi H, Khabazkhoob M, Kheirkhah A, Emamian MH, Mehravaran S, Shariati $M$, et al. Prevalence of dry eye syndrome in an adult population. Clin Exp Ophthalmol. 2014;42:242-8.

5. Lee AJ, Lee J, Saw SM, Gazzard G, Koh D, Widjaja D, et al. Prevalence and risk factors associated with dry eye symptoms: a population based study in Indonesia. Br J Ophthalmol. 2002:86:1347-51.

6. Moss SE, Klein R, Klein BE. Prevalence of and risk factors for dry eye syndrome. Arch Ophthalmol. 2000;118:1264-8.

7. Onwubiko SN, Eze BI, Udeh NN, Arinze OC, Onwasigwe EN, Umeh RE. Dry eye disease: prevalence, distribution and determinants in a hospital-based population. Cont Lens Anterior Eye. 2014;37:157-61.

8. Sendecka M, Baryluk A, Polz-Dacewicz M. Prevalence and risk factors of dry eye syndrome. Przegl Epidemiol. 2004;58:227-33.

9. Tan LL, Morgan P, Cai ZQ, Straughan RA. Prevalence of and risk factors for symptomatic dry eye disease in Singapore. Clin Exp Optom. 2015:98:45-53.

10. Uchino M, Nishiwaki Y, Michikawa T, Shirakawa K, Kuwahara E, Yamada M, et al. Prevalence and risk factors of dry eye disease in Japan: Koumi study. Ophthalmology. 2011;118:2361-7.

11. Vehof J, Kozareva D, Hysi PG, Hammond CJ. Prevalence and risk factors of dry eye disease in a British female cohort. Br J Ophthalmol. 2014;98:1712-7.

12. Zhang $Y$, Chen $H$, Wu X. Prevalence and risk factors associated with dry eye syndrome among senior high school students in a county of Shandong Province, China. Ophthalmic Epidemiol. 2012;19:226-30.

13. Um SB, Kim NH, Lee HK, Song JS, Kim HC. Spatial epidemiology of dry eye disease: findings from South Korea. Int J Health Geogr. 2014;13:31.

14. Stapleton F, Alves M, Bunya VY, Jalbert I, Lekhanont $K$, Malet F, et al. TFOS DEWS II epidemiology report. Ocul Surf. 2017;15:334-65. 
15. Malet F, Le Goff M, Colin J, Schweitzer C, Delyfer MN, Korobelnik JF, et al. Dry eye disease in French elderly subjects: the Alienor study. Acta Ophthalmol. 2014;92:e429-36.

16. Maruyama K, Yokoi N, Takamata A, Kinoshita S. Effect of environmental conditions on tear dynamics in soft contact lens wearers. Invest Ophthalmol Vis Sci. 2004:45:2563-8.

17. Porcar E, Pons AM, Lorente A. Visual and ocular effects from the use of flatpanel displays. Int J Ophthalmol. 2016;9:881-5.

18. Sayin N, Kara N, Pekel G, Altinkaynak H. Effects of chronic smoking on central corneal thickness, endothelial cell, and dry eye parameters. Cutan Ocul Toxicol. 2014;33:201-5.

19. Azuma M, Yabuta C, Fraunfelder FW, Shearer TR. Dry eye in LASIK patients. BMC Res Notes. 2014;7:420

20. Astakhov YS, Astakhov SY, Lisochkina AB. Assessment of dry eye signs and symptoms and ocular tolerance of a preservative-free lacrimal substitute (Hylabak (R)) versus a preserved lacrimal substitute (Systane (R)) used for 3 months in patients after LASIK. Clin Ophthalmol. 2013;7:2289-97.

21. Kastelan S, Lukenda A, Salopek-Rabatic J, Pavan J, Gotovac M. Dry eye symptoms and signs in long-term contact lens wearers. Coll Antropol. 2013; 37(Suppl 1):199-203

22. Welch D, Ousler GW 3rd, Nally LA, Abelson MB, Wilcox KA. Ocular drying associated with oral antihistamines (loratadine) in the normal population-an evaluation of exaggerated dose effect. Adv Exp Med Biol. 2002;506:1051-5.

23. Ohtsuki M, Yokoi N, Mori K, Matsumoto Y, Adachi W, Ishibashi K, et al. Adverse effects of beta-blocker eye drops on the ocular surface. Nippon Ganka Gakkai Zasshi. 2001;105:149-54.

24. Hallak JA, Tibrewal S, Jain S. Depressive symptoms in patients with dry eye disease: a case-control study using the Beck depression inventory. Cornea. 2015;34:1545-50

25. Labbe A, Wang YX, Jie Y, Baudouin C, Jonas JB, Xu L. Dry eye disease, dry eye symptoms and depression: the Beijing eye study. Br J Ophthalmol. 2013:97:1399-403.

26. Rentka A, Nagy A, Harsfalvi J, Szucs G, Szekanecz Z, Gesztelyi R, et al. Association between objective signs and subjective symptoms of dry eye disease in patients with systemic sclerosis. Rheumatol Int. 2017;37:1835-45.

27. Song H, Zhang M, Hu X, Li K, Jiang X, Liu Y, et al. Correlation analysis of ocular symptoms and signs in patients with dry eye. J Ophthalmol. 2017; 2017:1247138.

28. Nichols KK, Nichols JJ, Mitchell GL. The lack of association between signs and symptoms in patients with dry eye disease Cornea. 2004:23:762-70.

29. Amparo F, Schaumberg DA, Dana R. Comparison of two questionnaires for dry eye symptom assessment: the ocular surface disease index and the symptom assessment in dry eye. Ophthalmology. 2015;122:1498-503.

30. Asiedu K, Kyei S, Mensah SN, Ocansey S, Abu LS, Kyere EA. Ocular surface disease index (OSDI) versus the standard patient evaluation of eye dryness (SPEED): a study of a nonclinical sample. Cornea. 2016;35:175-80.

31. Messmer EM. The pathophysiology, diagnosis, and treatment of dry eye disease. Dtsch Arztebl Int. 2015;112:71-81.

32. Potvin R, Makari S, Rapuano CJ. Tear film osmolarity and dry eye disease: a review of the literature. Clin Ophthalmol. 2015;9:2039-47.

33. Bukhari A, Ajlan $\mathrm{R}$, Alsaggaf $H$. Prevalence of dry eye in the normal population in Jeddah, Saudi Arabia. Orbit. 2009;28:392-7.

34. Alshamrani AA, Almousa AS, Almulhim AA, Alafaleq AA, Alosaimi MB, Alqahtani AM, et al. Prevalence and risk factors of dry eye symptoms in a Saudi Arabian population. Middle East Afr J Ophthalmol. 2017;24:67-73.

35. Dougherty BE, Nichols JJ, Nichols KK. Rasch analysis of the ocular surface disease index (OSDI). Invest Ophthalmol Vis Sci. 2011;52:8630-5.

36. Craig JP, Nelson JD, Azar DT, Belmonte C, Bron AJ, Chauhan SK, et al. TFOS DEWS II report executive summary. Ocul Surf. 2017;15:802-12.

37. Jie $Y, X u L, W u Y Y$, Jonas JB. Prevalence of dry eye among adult Chinese in the Beijing eye study. Eye (Lond). 2009;23:688-93.

38. Viso E, Rodriguez-Ares MT, Gude F. Prevalence of and associated factors for dry eye in a Spanish adult population (the Salnes eye study). Ophthalmic Epidemiol. 2009;16:15-21.

39. Ayer L, Venkatesh B, Stewart R, Mandel D, Stein B, Schoenbaum M. Psychological aspects of the Israeli-Palestinian conflict: a systematic review. Trauma Violence Abuse. 2015;18(3):322.

40. Yilmaz U, Gokler ME, Unsal A. Dry eye disease and depression-anxiety-stress: a hospital-based case control study in Turkey. Pak J Med Sci. 2015;31:626-31.

41. Schaumberg DA, Sullivan DA, Buring JE, Dana MR. Prevalence of dry eye syndrome among US women. Am J Ophthalmol. 2003;136:318-26.
42. Hom M, De Land P. Prevalence and severity of symptomatic dry eyes in Hispanics. Optom Vis Sci. 2005:82:206-8.

43. Schein OD, Munoz B, Tielsch JM, Bandeen-Roche K, West S. Prevalence of dry eye among the elderly. Am J Ophthalmol. 1997;124:723-8.

44. Shimmura S, Shimazaki J, Tsubota K. Results of a population-based questionnaire on the symptoms and lifestyles associated with dry eye. Cornea. 1999:18:408-11.

45. Uchino M, Dogru M, Yagi Y, Goto E, Tomita M, Kon T, et al. The features of dry eye disease in a Japanese elderly population. Optom Vis Sci. 2006;83: 797-802.

46. Chia EM, Mitchell P, Rochtchina E, Lee AJ, Maroun R, Wang JJ. Prevalence and associations of dry eye syndrome in an older population: the Blue Mountains eye study. Clin Exp Ophthalmol. 2003;31:229-32.

47. Albietz JM. Prevalence of dry eye subtypes in clinical optometry practice. Optom Vis Sci. 2000;77:357-63.

48. McCarty CA, Bansal AK, Livingston PM, Stanislavsky YL, Taylor HR. The epidemiology of dry eye in Melbourne, Australia. Ophthalmology. 1998:105:1114-9.

49. Lin PY, Tsai SY, Cheng CY, Liu JH, Chou P, Hsu WM. Prevalence of dry eye among an elderly Chinese population in Taiwan: the Shihpai eye study. Ophthalmology. 2003;110:1096-101.

50. Lekhanont K, Rojanaporn D, Chuck RS, Vongthongsri A. Prevalence of dry eye in Bangkok, Thailand. Cornea. 2006:25:1162-7.

51. Sharma A, Hindman HB. Aging: a predisposition to dry eyes. J Ophthalmol. 2014;2014:781683

52. Titiyal JS, Falera RC, Kaur M, Sharma V, Sharma N. Prevalence and risk factors of dry eye disease in North India: ocular surface disease index-based crosssectional hospital study. Indian J Ophthalmol. 2018;66:207-11.

53. Paulsen AJ, Cruickshanks KJ, Fischer ME, Huang GH, Klein BE, Klein R, et al. Dry eye in the beaver dam offspring study: prevalence, risk factors, and health-related quality of life. Am J Ophthalmol. 2014;157:799-806.

54. Ferrero A, Alassane S, Binquet C, Bretillon L, Acar N, Arnould L, et al. Dry eye disease in the elderly in a French population-based study (the Montrachet study: maculopathy, optic nerve, nuTRition, neurovAsCular and HEarT diseases): prevalence and associated factors. Ocul Surf. 2018;16:112-9.

55. Wolffsohn J, Arita R, Chalmers R, Djalilian A, et al. TFOS DEWS II diagnostic methodology report. The Ocular Surface. 2017;15:539-74.

\section{Publisher's Note}

Springer Nature remains neutral with regard to jurisdictional claims in published maps and institutional affiliations.
Ready to submit your research? Choose BMC and benefit from:

- fast, convenient online submission

- thorough peer review by experienced researchers in your field

- rapid publication on acceptance

- support for research data, including large and complex data types

- gold Open Access which fosters wider collaboration and increased citations

- maximum visibility for your research: over $100 \mathrm{M}$ website views per year

At BMC, research is always in progress.

Learn more biomedcentral.com/submissions 